\title{
Noninvasive ventilation: a decade of progress
}

\author{
M. Elliott*, N. Ambrosino ${ }^{\#}$
}

During the 1990s, noninvasive ventilation moved from being almost unknown outside a few specialist centres to becoming a cornerstone in the management of patients with respiratory failure. As with many advances in medicine, the basic idea is not new. Indeed, the technique is almost as old as mankind itself. In Genesis, Chapter 2, verse 7 it is stated that "the Lord God formed the man from the dust of the ground and breathed into his nostrils the breath of life". Sustained artificial ventilation of humans was first explored in the mid-1700s using bellows and a tracheal tube in an attempt to resuscitate those who had drowned. However, following a dramatic series of experiments, which demonstrated fatal pneumothorax in animals subjected to ventilation with pressures greatly in excess of those likely in clinical practice, the technique was quickly condemned and banned from clinical practice in its infancy. Negative pressure devices were developed as an alternative, but only found widespread clinical use when the Drinker-Shaw iron lung was developed in 1928 [1]. For many years, external negative pressure was used for the treatment of respiratory paralysis, secondary to poliomyelitis. Positive pressure ventilation was only used in clinical practice during anaesthesia in the operating room. However, during the Copenhagen polio epidemic in the 1950s there were insufficient negative pressure ventilators available, so patients were intubated and hand ventilated by teams of technicians and students working round the clock in shifts. Survival rates using positive pressure ventilation were much better than those observed during use of negative pressure ventilation during the early stages of the epidemic, an improvement thought to be related to better airway protection from aspiration of secretions. Once it was acknowledged that prolonged tracheal intubation was safe, positive pressure ventilation via endotracheal tube became the treatment of choice whenever mechanical ventilation was required. Negative pressure ventilation was only used in a few specialist centres for the management of patients with chronic ventilatory failure requiring long-term mechanical ventilation at home.

The noninvasive application of positive pressure dates back to the 1930s, when BARACH et al. [2]

\footnotetext{
*St James's University Hospital, Leeds, UK and ${ }^{*} \mathrm{~S}$. Maugeri Foundation, Scientific Institute of Gussago, Pulmonary Division, Gussago, Italy.

Correspondence: M. Elliott, St James's University Hospital, Beckett Street, Leeds, LS9 7TF, UK. Fax: 44 1132066042. E-mail: mark_w. elliott@leedsth.NHS.UK
}

demonstrated that continuous positive airway pressure (CPAP) could be useful in the treatment of acute pulmonary oedema. Intermittent positive pressure breathing (IPPB), in which gas flow from a machine ceased when a predetermined pressure was reached, via a mouthpiece was first described in the late 1940s [3]. In general, IPPB was prescribed either as a mode of delivering a therapeutic aerosol and/or for the purpose of assisting ventilation and decreasing the work of breathing. However, although short-term studies showed a physiological effect [4, 5], clinical studies showed no consistent benefits to patients. In the largest series, 985 patients with chronic obstructive pulmonary disease (COPD) were randomized to IPPB or conventional therapy [6]. There were no statistically significant differences in mortality, need for hospitalization, change in lung function or quality of life during an average follow-up of 33 months. Patients were asked to use IPPB for $10 \mathrm{~min}$, three times a day, during which time they inhaled a $\beta$-agonist generated by the machine's nebulizer. The control group had the same treatment administered by compressor over the same time. Despite this relatively undemanding treatment schedule, only $50 \%$ of the patients complied with the protocol and $20 \%$ used their machines for $<10 \mathrm{~min} \cdot \mathrm{day}^{-1}$. The most likely explanation for this lack of compliance is that the patients failed to notice any benefit and, therefore, did not continue the treatment.

Noninvasive positive pressure ventilation (NPPV), administered nocturnally and as needed during the daytime, mainly via mouthpiece, was used successfully to treat patients with neuromuscular disease in the early 1960s [7]. However, the technique did not gain acceptance outside a few specialist centres. Face masks were also available, but these also failed to gain wide acceptance for the chronic administration of noninvasive ventilation, largely because of poor patient tolerance. In the early 1980s, CPAP delivered through a nasal mask [8] was described in the treatment of obstructive sleep apnoea. With the realization that patients could tolerate positive pressure delivered through a well-fitting nasal mask during sleep, NPPV was developed for the management of chronic nocturnal hypoventilation. In the last decade, the technique has leapt to prominence; as experience was gained, the indications widened and NPPV became available in many more centres.

Another aspect of the growth of noninvasive ventilation is worthy of comment. High technology interventions are usually developed in hospital, and, 
after considerable experience has been gained in this setting, a few are extended into the home. For example, home parenteral nutrition was only attempted after the techniques were well developed in hospitalized patients. NPPV first made its mark in the home environment, but as confidence grew, patients with acute on chronic ventilatory failure were ventilated in hospital, and now the noninvasive approach is considered by some to be the treatment of choice for acute ventilatory failure of whatever aetiology [9]. Because ventilation can be assisted without the need for paralysing and sedating drugs, patients do not need continuous one-to-one nursing care and assisted ventilation for acute ventilatory failure outside the intensive care unit (ICU) has become a feasible option. There is now an ever-growing body of prospective randomized control data to inform medical practice, and it is likely that, just as NPPV has been described as "a new standard of care" in patients admitted to hospital with an acute exacerbation of COPD [10], it will assume a still greater role in the management of acutely ill patients with respiratory disease from other aetiologies.

Endotracheal intubation (ETI), for so long necessary to provide ventilatory support, is not without its problems. Indeed, its necessity for treating ventilatory failure brings with it a predisposition to various complications, particularly nosocomial infection. In intubated patients, there is a $1 \%$ risk $\cdot$ day $^{-1}$ of developing nosocomial pneumonia [11]. This complication of invasive ventilation is associated with a longer ICU stay, increased costs and a worse outcome [12]. A reduction in the incidence of nosocomial infection is a consistent and important advantage of NPPV compared with invasive ventilation [13-18] and is probably the most important advantage of avoiding ETI using NPPV. Indeed, ventilator-associated pneumonia is probably now better described as "tubeassociated pneumonia" because it is the endotracheal tube rather than the ventilator that is responsible.

In the next few issues of the European Respiratory Journal a review series will consider: the evidence base for the use of noninvasive ventilation in acute and chronic respiratory failure; where and when it should be instituted; and the infrastructure and equipment needed for both an acute and a chronic service. The particular needs of children will also be addressed. As increasing numbers of patients with significant cardiorespiratory disease are treated on the ICU, or require ventilatory support following emergency surgery, there is a growing need for new approaches in the weaning of these patients from mechanical ventilation. Noninvasive ventilation holds promise for some patients who are difficult to wean. Finally, the role of negative pressure ventilation, in some ways the "father" of NPPV, will be addressed. There is a saying that "what goes around comes around", and it may be that negative pressure ventilation will make a resurgence in the future. Ventilation achieved through an augmented negative intrathoracic pressure is certainly more physiological than positive pressure, and there is already evidence that it has a particular role for children who are undergoing complex cardiac surgery
[19, 20]. However, NPPV remains the noninvasive mode of choice for most situations.

Noninvasive positive pressure ventilation has been a real and significant advance in the treatment of patients with both acute and chronic respiratory failure. The next few years are likely to see further technological advances, and future research will position noninvasive positive pressure ventilation more accurately in the therapeutic armamentarium of physicians dealing with patients with both acute and chronic respiratory failure.

\section{References}

1. Drinker P, Shaw LA. An apparatus for the prolonged administration of artificial ventilation. $J$ Clin Invest 1929; 7: 229-247.

2. Barach AL, Martin J, Eckman M. Positive pressure respiration and its application to the treatment of acute pulmonary edema. Ann Intern Med 1938; 12: 754-795.

3. Motley HL, Werko L, Cournand A, Richards DW. Observations on the clinical use of positive pressure. J Aviation Med 1947; 18: 417-435.

4. Sukulmalchantra Y, Park SS, Williams MH. The effects of intermittent positive pressure breathing (IPPB) in acute ventilatory failure. Am Rev Respir Dis 1965; 92: 885-893.

5. Fraimow W, Cathcart RT, Goodman E. The use of intermittent positive pressure breathing in the prevention of carbon dioxide narcosis associated with oxygen therapy. Am Rev Respir Dis 1960; 81: 815-822.

6. The Intermittent Positive Pressure Breathing Trial Group. Intermittent positive pressure breathing therapy of chronic obstructive pulmonary disease. Ann Intern Med 1983; 99: 612-620.

7. Alba A, Khan A, Lee M. Mouth IPPV for sleep. Rehabilitation Gazette 1984; 24: 47-49.

8. Sullivan CE, Berthon-Jones M, Issa FG. Reversal of obstructive sleep apnoea by continuous positive airway pressure applied through the nares. Lancet 1983; 1: 862-865.

9. Meduri GU, Turner RE, Abou-Shala N, Wunderink $\mathrm{R}$, Tolley E. Noninvasive positive pressure ventilation via face mask. First-line intervention in patients with acute hypercapnic and hypoxemic respiratory failure. Chest 1996; 109: 179-193.

10. Brochard L. Non-invasive ventilation for acute exacerbations of COPD: a new standard of care. Thorax 2000; 55: 817-818.

11. Fagon JY, Chastre J, Hance A, Montravers P, Novara A, Gibert C. Nosocomial pneumonia in ventilated patients: a cohort study evaluating attributable mortality and hospital stay. Am J Med 1993; 94: 281287.

12. Torres A, Aznar R, Gatell JM. Incidence, risk and prognosis factors of nosocomial pneumonia in mechanically ventilated patients. Am Rev Respir Dis 1990; 142: 523-528.

13. Brochard L, Mancebo J, Wysocki M, et al. Noninvasive ventilation for acute exacerbations of chronic obstructive pulmonay disease. $N$ Engl J Med 1995; 333: 817-822.

14. Nava S, Ambrosino N, Clini E, et al. Noninvasive mechanical ventilation in the weaning of patients 
with respiratory failure due to chronic obstructive pulmonary disease. A randomized, controlled trial. Ann Intern Med 1998; 128: 721-728.

15. Antonelli M, Conti G, Rocco M, et al. A comparison of noninvasive positive-pressure ventilation and conventional mechanical ventilation in patients with acute respiratory failure. $N$ Engl J Med 1998; 339: 429435.

16. Hilbert G, Gruson D, Vargas F, et al. Noninvasive ventilation in immunosuppressed patients with pulmonary infiltrates, fever, and acute respiratory failure. $N$ Engl J Med 2001; 344: 481-487.

17. Nourdine K, Combes P, Carton M-J, Beuret P, Cannamela A, Ducreux J-C. Does noninvasive ventilation reduce the ICU nosocomial infection risk? A prospective clinical survey. Intensive Care Med 1999; 25: $567-573$.

18. Girou E, Schortgen F, Delclaux C, et al. Association of noninvasive ventilation with nosocomial infections and survival in critically ill patients. JAMA 2000; 284 : 2361-2367.

19. Shekerdemian LS, Schulze-Neick I, Redington AN, Bush A, Penny DJ. Negative pressure ventilation as haemodynamic rescue following surgery for congenital heart disease. Intensive Care Med 2000; 26: 93-96.

20. Shekerdemian LS, Bush A, Lincoln C, Shore DF, Petros AJ, Redington AN. Cardiopulmonary interactions in healthy children and children after simple cardiac surgery: the effects of positive and negative pressure ventilation. Heart 1997; 78: 587-593. 